\title{
Mucinous adenocarcinoma of the appendix presenting with atypical symptomatology and presence of pseudomyxoma peritonei: a case report
}

\author{
Konstantinos Alexiou ${ }^{1}$, Nikolaos Sikalias*1, Maria Demonakou ${ }^{2}$, Sylvia- \\ Christina Mylona1, Vasileios Triantafyllis ${ }^{1}$, Asimina Kalogirou ${ }^{2}$ and \\ Georgios Antsaklis ${ }^{1}$
}

\begin{abstract}
Address: ${ }^{1}$ Department of Surgery, "Sismanoglio" General Hospital of Athens, (Sismanogliou 1), Marousi - Athens (15126), Greece and 2Department of Anatomical Pathology, "Sismanoglio" General Hospital of Athens, (Sismanogliou 1), Marousi - Athens (15126), Greece

Email: Konstantinos Alexiou - knegro@otenet.gr; Nikolaos Sikalias* - niksikalias@aol.com;

Maria Demonakou - mariademonakou@hotmail.com; Sylvia-Christina Mylona - sylviamylona@yahoo.com;

Vasileios Triantafyllis - vtriantafyllis@yahoo.gr; Asimina Kalogirou - nsikdoc@freemail.gr; Georgios Antsaklis - georgeantsaklis@hotmail.com

* Corresponding author
\end{abstract}

Published: 25 November 2009

Cases Journal 2009, 2:9089 doi:10.1/86/1757-1626-2-9089

This article is available from: http://www.casesjournal.com/content/2/I/9089

(C) 2009 Alexiou et al; licensee BioMed Central Ltd.

This is an Open Access article distributed under the terms of the Creative Commons Attribution License (http://creativecommons.org/licenses/by/2.0), which permits unrestricted use, distribution, and reproduction in any medium, provided the original work is properly cited.
Received: 20 October 2009

Accepted: 25 November 2009

\begin{abstract}
Introduction: Primary tumors of the appendix are unusual and most of them are carcinoids. Their main presentation is that of an acute appendicitis or as a palpable mass, mainly in the right lower quadrant.
\end{abstract}

Case presentation: A female patient with mucous adenocarcinoma of the appendix, which primarily presented as atypical abdominal pain. Diagnosis of the disease was made after appendicectomy and histopathological analysis of the specimen. The patient finally underwent a complementary right hemicolectomy.

Conclusion: Mucin producing adenocarcinomas of the appendix are a category of rare cancers of the gastrointestinal tract. Although at present they are a well studied pathologic entity, the crucial issue of their preoperative diagnosis remains unsolved.

\section{Introduction}

Primary tumors of the appendix are unusual and most of them (almost 85\%) are carcinoids [1]. Adenocarcinomas of the appendix are a category of rare tumors of the gastrointestinal tract, with a frequency of $0,2 \%-0,5 \%$ of all intestinal malignancies and $4 \%-6 \%$ over neoplasmatic lesions of the appendix $[2,3]$. The first case of a primary adenocarcinoma of the appendix was reported by Berger on 1882[4]. Mucin-producing cystedenocarcinomas or mucous adenocarcinomas, and non-mucin producing or colonic type adenocarcinomas are included in this category.

The main presentation of these tumors is that of an acute appendicitis (30\%-50\%) or as a palpable mass mainly in the right lower quadrant [3]. Less frequently they may present in female patients as an ovarian tumor [4]. Nevertheless mucous adenocarcinomas are reported as having the greatest tendency among tumors to perforate, leading occasionally to the formation of pseudomyxoma peri- 
tonei (PMP)[3]. This specific image is met in $0,2 \%-0,3 \%$ of all appedicectomies and comprises an uncommon and poorly studied situation with gelatinous ascitic collection and multiple mucous peritoneal implantations. In the case of benign cystadenoma, perforation causes the formation of localized collections, while in malignant adenocarcinomas mucous is spread and abundant [5]. Treatment of PMP comprises of surgical debulging of the peritoneal cavity, appendicectomy, omentectomy and bilateral oophorectomy in women. This treatment is proposed by different studies, showing that the primary location of the adenocarcinoma is almost exclusively the appendix and suggesting that ovarian carcinomas are in fact secondary metastases $[1,3]$.

\section{Case presentation}

A Caucasian 64-year old female Greek patient presented with hypogastric and right lower quadrant abdominal pain, which started 24 hours before, without other pathological findings in the clinical examination. Laboratory tests on admission showed: WBC: $7.200 / \mathrm{mm}^{3}$ (with normal type), Hb:13,3 g/dl, Hct:40\% and normal coagulation values. The patient was hospitalized for further investigation and underwent medical treatment for 6 days. Ultrasonography of the lesser pelvis showed a small quantity of free liquid located in the Douglas area and the right parametrium. Computed tomography of the pelvis reported normal internal organs (uterus, ovaries) and the patient was relegated for gynaecological evaluation after the initial clinical symptoms were minimized. One month later the patient presented again with the same abdominal pain. The diagnosis of acute appendicitis was set and the patient underwent an open laparotomy on a Mac Burney section. During the operation a dense and diffuse myxomatous collection was found around the appendix. Appendicectomy took place as well as thorough cleaning of the peritoneal cavity. Histological examination of the specimen revealed a mucous adenocarcinoma of the appendix [Fig 1,2] which was classified as stage $B$ $\left(\mathrm{T}_{3} \mathrm{~N}_{0} \mathrm{M}_{0}\right)$ on Duke's staging system (Astler Coller modification)[2]. The patient was then scheduled for a second operation and underwent a right hemicolectomy, which is proposed as the treatment of choice for this type of neoplasms. Since there was no evidence of synchronous presence of ovarian tumor, no additional oophorectomy was performed.

\section{Discussion}

A retrograde study was performed concerning the appendicectomies that took place in General Hospital Sismanogleio over a ten year period between 1998 - 2008. A total of 2148 appendicectomies was performed $(47,75 \%$ males, 52,25\% females). Eleven (12) cases of primary appendiceal neoplasms were identified (frequency $0,37 \%)$, eight (8) of them being mucin-producing enti-

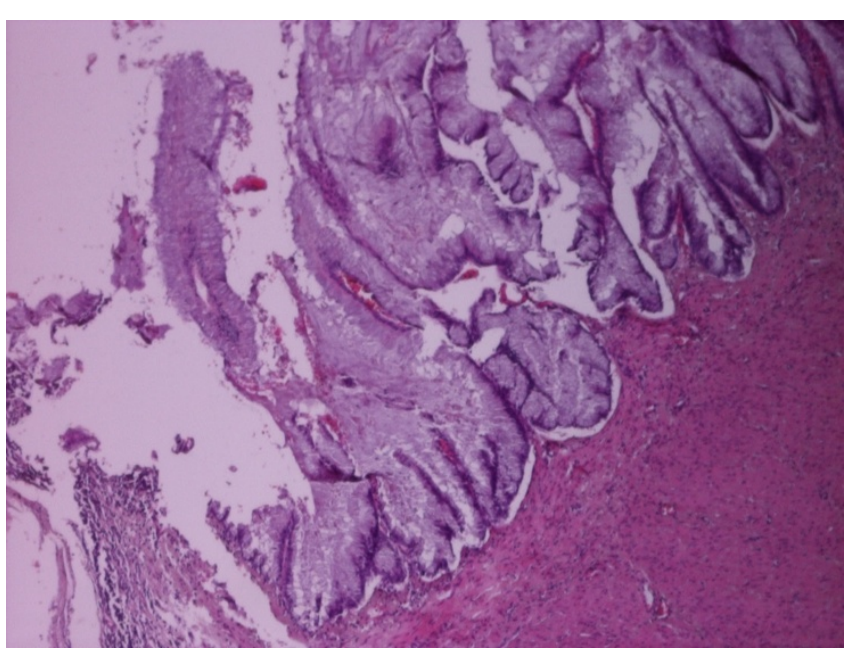

\section{Figure I}

(HEx I0) A well differentiated mucous producing appendicial neoplasm without invasion of the stroma.

ties. Only one was positively identified as a mucous adenocarcinomas and right hemicolectomy with synchronous oophorectomy was performed as treatment of choice. Four (4) tumors of endocrine origin were recognized (frequency $0,19 \%$ ) three (3) of them being benign carcinoids and one of uncertain classification. For this last case, right hemicolectomy was performed and diagnosis of the tumoral character was set after proper laboratory analysis. Carcinoids of the appendix are of low malignancy (>90\%, 5 -year survival) compared to those developing in other organs and simple appendicectomy is sufficiently curative when their size is not over $1,5 \mathrm{~cm}$. They rarely reach sizes over $2 \mathrm{~cm}$ and in this case they are considered to be malig-

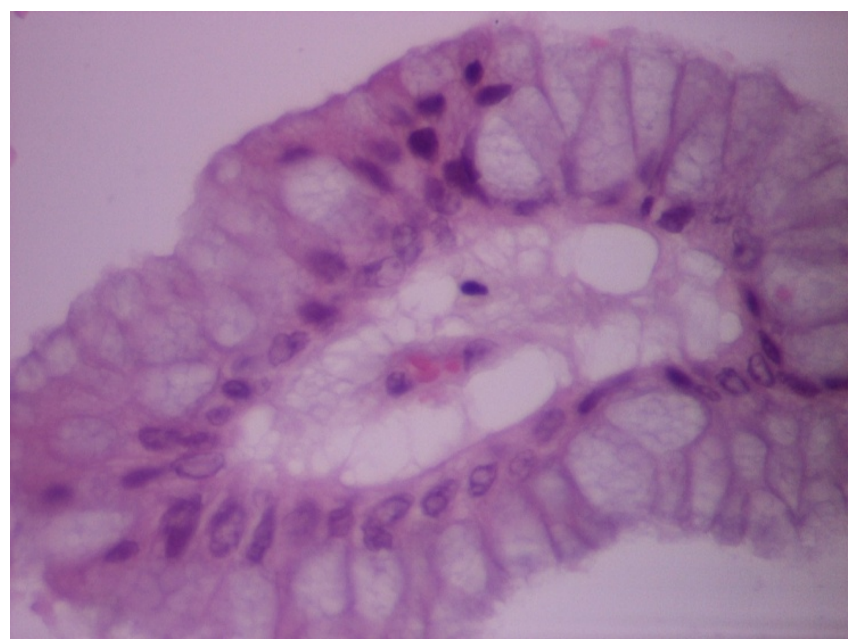

Figure 2

(HEX40) Ville of the neoplasm covered by mucin producing cells with minimal atypia. 
nant and right hemicolectomy is indicated [1]. Epithelial tumors of the appendix are not frequent and might be benign (adenomas) or malignant (adenocarcinomas), which further divide in mucous and non-mucous adenocarcinomas $[1,6]$. Concerning their etiology, mucous adenocarcinomas are generally accepted to arise in preexisting cystadenomas[1,2]. In general, mucous adenocarcinomas have better prognosis than those of colonic type/ non-mucous ones. Treatment of choise is considered to be right hemicolectomy.

Positive diagnosis for these tumors is generally set after their histologic identification; nevertheless criteria should be set for preoperative recognition, in order to perform the treatment of choice in the first place. Among imaging methods CT scan offers 95\% sensitivity for carcinomas of the appendix. As reported in related studies of preoperative CT sections in patients diagnosed with appendiceal cancer, morphological changes and alterations in the dimensions of the appendix can guide the diagnosis. $100 \%$ of cases had evidence of altered morphology of the appendix and increased dimensions (max diameter 1,3 $6,0 \mathrm{~cm}$ and max thickness of the appendiceal wall of 0,4 $2.0 \mathrm{~cm}$.)[7].

Moreover, the presence of a cystic mass may suggest the presence of cystadenoma or cystadenocarcinoma[8]. Nevertheless, since the usual presentation of the disease is that of acute appendicitis, the preoperative positive diagnosis still remains impossible[3].

\section{Conclusion}

Mucin producing adenocarcinomas of the appendix are a category of rare cancers of the gastrointestinal tract. Although at present they are a well studied pathologic entity, the crucial issue of their preoperative diagnosis remains unsolved.

\section{Abbreviations}

PMP: pseudomyxoma peritonei; WBC: white blood cells; Hb: Hemoglobin; Hct: hematocrit; CT: computed tomography; TNM: Classification of Malignant Tumours (Tumor size, lymph Nodes, and Metastasis).

\section{Consent}

Written informed consent was obtained from the patient for publication of this case report and accompanying images. A copy of the written consent is available for review by the Editor-in-Chief of this journal.

\section{Competing interests}

The authors declare that they have no competing interests.

\section{Authors' contributions}

KA, NS, GA have had an equally substantial contribution to the clinical diagnosis, surgical management and postop follow-up of the patient. MD and AK performed the histological examination KA, NS and MD performed the retrograde study, SCM and VT drafted the manuscript. NS and GA are guarantors of the paper. All authors read and approved the final manuscript.

\section{References}

I. Pickhart PJ, Levy AD, Rohrmann CA, Kende Al: Primary Neoplasms of the Appendix: Radiologic Spectrum of Disease with Pathologic Correlation. RadioGraphics 2003, 23(3):645-662.

2. Hananel N, Powsner E, Wolloch Y: Adenocarcinoma of the appendix: an unusual disease. Eur J Surg 1998, 164:859-862.

3. Cortina R, McCormick J, Kolm P, Perry RR: Management and prognosis of adenocarcinoma of the appendix. Dis Colon Rectum 1995, 38(8):848-852.

4. Umemoto $M$, Shiota $M$, Shimaoka M, Hoshiai H: Definitive diagnosis of primary adenocarcinoma of the appendix by laparoscopic appendectomy. J Obstet Gynaecol Res 2007, 33(4):590-594.

5. Lin CY, Hsu HM, Gao HW, Liu YC, Yu JC: Synchronous adenocarcinoma of the appendix and transverse colon associated with pseudomyxoma peritonei presenting as an acute appendicitis. J Med Sci 2003, 23(2): I $3|-| 34$.

6. McCusker M, Cote TR, Clegg LX, Sobin LH: Primary malignant neoplasms of the appendix, a population-based study from the surveillance, epidemiology and end-results program, 1973-1998. Cancer 2002, 94(I 2):3307-33I2.

7. Pickhart PJ, Levy AD, Rohrmann CA, Kende Al: Primary Neoplasms of the Appendix Manifesting as Acute Appendicitis: CT findings with Pathologic Comparison. Radiology 2002, 224(3):775-78I.

8. Tan A, Lau PH: Sonography of Primary Adenocarcinoma of the Appendix with Pathological Correlation. The Am J of Gastrenterology 1983, 78(8):488-492.
Publish with BioMed Central and every scientist can read your work free of charge

"BioMed Central will be the most significant development for disseminating the results of biomedical research in our lifetime." Sir Paul Nurse, Cancer Research UK

Your research papers will be:

- available free of charge to the entire biomedical community

- peer reviewed and published immediately upon acceptance

- cited in PubMed and archived on PubMed Central

- yours - you keep the copyright

Submit your manuscript here:

http://www.biomedcentral.com/info/publishing_adv.asp
BioMedcentral 